\title{
Research on the Development Strategy of Dujiangyan's Cultural Tourism Based on Tourist Satisfaction
}

\author{
Weiting Zhu, Heng Yang*, Shuhua Zhang, Hui He \\ College of Tourism, \\ Sichuan Agricultural Uniersity \\ Chengdu, China \\ 21834566@qq.com
}

\begin{abstract}
By investigating tourists'perception and satisfaction in Dujiangyan, this paper finds out the significant influencing factors of Tourists'Perception in Dujiangyan, and discusses the development strategy of Dujiangyan cultural tourism based on tourists'satisfaction. Firstly, this paper provides a brief overview of Dujiangyan cultural tourism resources; secondly, according to the theory of tourists'satisfaction and Dujiangyan tourism resources, it selects the evaluation index of tourists' satisfaction to form a questionnaire. Then it analyzes the tourist market of Dujiangyan from the perspective of demography and tourists'behavior characteristics, and makes an empirical analysis of the current situation of Dujiangyan's satisfaction, and puts forward the corresponding development strategies of cultural experience tourism from the perspective of improving tourists' satisfaction. The results of this study are expected to provide some references for promoting the development of cultural tourism in Dujiangyan and the construction of famous international tourist cities.
\end{abstract}

Keywords-Tourist satisfaction; Cultural tourism; Tourism development; Dujiangyan

\section{INTRODUCTION}

Tourist satisfaction refers to a psychological state produced by comparing the tourists'psychological expectation of the destination before traveling with the tourists' actual perception after visiting the destination. It is the process and result of tourists'psychological comparison, that is, if the actual experience and evaluation of tourism are greater than or equal to the tourists' expectation, tourists will be able to make the tourists. The satisfaction of visitors is satisfied; otherwise, tourists will be dissatisfied [1-4]. Throughout the study of tourist satisfaction at home and abroad, the object of study includes tourism products at the micro level, tourism industry at the macro level and tourism industry at the macro level [2-6]. Domestic scholars mostly focus on the case study of tourist satisfaction system. Satisfactory evaluation based on tourism product development and marketing strategy is an important direction of tourist satisfaction research [2-7]. From the perspective of tourists, through the satisfaction assessment to understand and grasp the level of tourism services, tourism attractiveness and tourism competitiveness of tourist destinations. Establishing an evaluation mechanism for tourists to enhance the competitiveness of tourism destinations and the

Deep excavation of cultural elements in Dujiangyan and its tourism product construction (2017, number 2017M02). endogenous mechanism of tourism economic development [7]. With the intensification of tourism market competition and the change of tourists'consumption concept, tourists' satisfaction has become the core and key to the survival and development of tourist destinations and the sustainable development of the tourism industry [8-10].

In recent years, cultural tourism has developed vigorously. Dujiangyan (hereafter, "DJY") is the capital with a long history and culture. However, theoretical research on cultural tourism in DJY is relatively weak. The research mainly focuses on the development of tourism resources and products in DJY, and tries to forget about the cultural tourism market.Using the theory of tourist satisfaction, this paper evaluates the tourist satisfaction of DJY, explores significant influencing factors of tourist satisfaction of DJY, and the development strategy of DJY cultural tourism based on satisfaction from the perspective of tourism market.

\section{DJY TOURISM RESOURCES REVIEW}

DJY was once the most developed central area of ancient Shu. Its unique geographical position is making DJY become the intersection point of various cultures. The evolution of several thousand years has brewed a rich cultural connotation and abundant tourism resources. DJY is an important aspect of the giant panda habitat of the world's natural heritage, Sichuan. DJY Qingcheng Mountain (hereafter, "QCM"), a world cultural heritage, has been testified to a long history. It has the tourism resources of typical historical relics in China. The ancient city of DJY Guanxian is the first historic step for ancient Shu people to walk out of the mountain area and enter the plain. It has profound cultural background. It has Taoist QCM, Buddhist temple Lingyan Temple and other religious tourism resources, as well as national intangible cultural heritage DJY Drainage Festival, Sichuan intangible cultural heritage Qingcheng Wushu, Qingcheng Cave classical music, Wangnangtan legend and other intangible cultural heritage resources.In recent years, DJY has held annually a double legacy marathon, China (Chengdu) - India International Yoga Festival, Western Music Festival, Munich Beer Festival and other large-scale festivals. Colorful and unique tourism resources are the competitive advantages of DJY's cultural tourism. 


\section{RESEARCH IDEAS AND RESEARCH METHODS}

\section{A. Research Ideas}

In this paper, DJY City as the research area, DJY tourists as the research object, using questionnaires to evaluate the satisfaction of DJY tourists, to explore the significant factors affecting the satisfaction of DJY tourists, and put forward the corresponding development strategy of DJY cultural tourism. Because tourist satisfaction is the evaluation of tourists'expectation and perceived quality, the factors affecting tourist satisfaction should cover all aspects of tourist destination [11], such as tourism resources, tourism environment, and infrastructure of scenic spots, food, accommodation, shopping, and entertainment and tourism services. Therefore, this paper constructs the index system of tourists'satisfaction in DJY [12], including 9 evaluation dimensions and 42 evaluation factors (Table I). The questionnaire consists of 3 parts. (1) Survey on the demographic information and behavior of the respondents: including gender, age, educational background, occupation, monthly income, source of visitors, mode of travel, purpose of travel, information sources, etc. (2) evaluation of respondents' Tourism expectation and actual perceived quality.(3) the overall satisfaction and loyalty of tourists. The Likert 5 scale was used to evaluate the subjective attitude of the respondents to the questionnaire.

\section{B. Research Methods}

During September 2018, 125 questionnaires were sent out through the questionnaire star, 106 valid questionnaires, the effective recovery rate was $84.8 \%$. Statistical analysis software SPSS 20 was used to analyze the sample data of the questionnaire and draw a conclusion.

\section{SURVEY DATA ANALYSIS}

\section{A. Demographic Characteristics of Tourists}

The sex ratio of the tourists surveyed was $49 \%$ for males and $51 \%$ for females. The age structure showed that the respondents were mainly $18-29$ and 30-44 years old, being accountable for $55 \%$ and $32 \%$ respectively. The tourists had a higher education level, mainly college and undergraduate education. Most of the tourists in DJY are employed, freelancers and students. The monthly income level of tourists is mainly 2001-4000 yuan. (Table II)

\section{B. Analysis of Tourist Behavior Characteristics}

Investigation and analysis showed that DJY tourists mainly came from Sichuan Province, making up 69\%. Tourists are primarily self-help tourism, accounting for $80 \%$; most choose high-speed rail, trains, buses and other means of transport, accounting for $24 \%, 19 \%, 15 \%$; a small number of tourists stay in DJY. Tourists'motivation is mainly sightseeing and leisure, accounting for more than $60 \%$; Tourists' access to tourism information in DJY mainly comes from Internet publicity and interpersonal communication. The most attractive tourist resources in DJY are: DJY Water Conservancy Project, Qingcheng Mountain, Guanxian Ancient City, Panda Base and Panda Valley.
TABLE I. EVALUATION INDEX SYSTEM OF TOURIST SATISFACTION IN DJY

\begin{tabular}{|c|c|c|}
\hline Total goal & $\begin{array}{c}\text { Evaluation } \\
\text { dimension }\end{array}$ & Evaluation factor \\
\hline \multirow{9}{*}{$\begin{array}{l}\text { Tourist } \\
\text { Satisfaction } \\
\text { and } \\
\text { Visitor } \\
\text { Loyalty }\end{array}$} & $\begin{array}{l}\text { Tourists } \\
\text { Expectation }\end{array}$ & $\begin{array}{l}\text { Overall expectations before travel, } \\
\text { Tourism products meet demand before } \\
\text { Tourism. }\end{array}$ \\
\hline & $\begin{array}{l}\text { Tourism } \\
\text { Resources }\end{array}$ & $\begin{array}{l}\text { DJY water conservancy project, QCM, } \\
\text { Li Bing culture, Qingcheng martial } \\
\text { arts, Dongjing ancient music, Ancient } \\
\text { city of Guan County, Panda base, Bear } \\
\text { cat Valley. }\end{array}$ \\
\hline & $\begin{array}{l}\text { Tourism } \\
\text { Environmen } \\
\mathrm{t}\end{array}$ & $\begin{array}{l}\text { Climate and environment, Air quality, } \\
\text { Water quality }\end{array}$ \\
\hline & $\begin{array}{l}\text { Scenic } \\
\text { Infrastructur } \\
\text { e }\end{array}$ & $\begin{array}{l}\text { Scenic area road indication, Tour point } \\
\text { introduction, Tour design, Scenic } \\
\text { safety protection facilities, Tour guide } \\
\text { explanation, The degree of civilization } \\
\text { in the scenic area, Crowding in scenic } \\
\text { spots, Sanitary condition of scenic } \\
\text { spots }\end{array}$ \\
\hline & $\begin{array}{l}\text { Tourist } \\
\text { Accommoda } \\
\text { tion }\end{array}$ & $\begin{array}{l}\text { Catering environment, Catering } \\
\text { services, Catering prices, Catering } \\
\text { features, Food and beverage hygiene }\end{array}$ \\
\hline & $\begin{array}{l}\text { Tourist } \\
\text { Catering } \\
\end{array}$ & $\begin{array}{l}\text { Accommodation conditions, } \\
\text { Accommodation price, Hotel Service }\end{array}$ \\
\hline & $\begin{array}{l}\text { Tourist } \\
\text { Traffic }\end{array}$ & $\begin{array}{l}\text { External traffic accessibility, Internal } \\
\text { traffic convenience, A parking lot, } \\
\text { Road traffic sign }\end{array}$ \\
\hline & $\begin{array}{l}\text { Tourism } \\
\text { Activities }\end{array}$ & $\begin{array}{l}\text { Tourism activities have local } \\
\text { characteristics, Participatory and } \\
\text { experiential activities, Activity interest }\end{array}$ \\
\hline & $\begin{array}{l}\text { Tourism } \\
\text { Service }\end{array}$ & $\begin{array}{l}\text { Shopping places, Entertainment } \\
\text { places, Public toilets, Friendly degree } \\
\text { of local residents, Complaints } \\
\text { accepted, Characteristic tourist } \\
\text { souvenirs }\end{array}$ \\
\hline
\end{tabular}

TABLE II. DEMOGRAPHIC CHARACTERISTICS OF TOURISTS

\begin{tabular}{|c|c|c|}
\hline Item & Content & Percent \\
\hline \multirow[t]{2}{*}{ Sex } & Male & 49 \\
\hline & Female & 51 \\
\hline \multirow[t]{5}{*}{ Age } & Under 18 years of age & 1 \\
\hline & $18-29$ years old & 55 \\
\hline & $30-44$ years old & 32 \\
\hline & $45-55$ years old & 12 \\
\hline & Over 55 years of age & 0 \\
\hline \multirow{4}{*}{$\begin{array}{l}\text { Educational } \\
\text { level }\end{array}$} & Junior high school and below & 2 \\
\hline & High school & 6 \\
\hline & Junior college and undergraduate degree & 73 \\
\hline & Master's degree or above & 19 \\
\hline \multirow[t]{7}{*}{ Occupation } & Civil servant & 2 \\
\hline & Institution & 13 \\
\hline & Enterprise staff & 42 \\
\hline & Individual operator & 10 \\
\hline & student & 16 \\
\hline & Free Professional & 17 \\
\hline & Retiree & 0 \\
\hline \multirow{5}{*}{$\begin{array}{l}\text { Monthly } \\
\text { income }\end{array}$} & Less than 2000 yuan & 19 \\
\hline & 2001-4000 yuan & 25 \\
\hline & 4001-6000 yuan & 31 \\
\hline & $6001-8000$ yuan & 12 \\
\hline & More than 8000 yuan & 13 \\
\hline
\end{tabular}




\section{Analysis of Tourist Satisfaction Results}

Through statistical analysis, the evaluation value of tourist satisfaction is 3.82, indicating that the overall satisfaction of tourists to DJY tourism has not achieved a satisfactory level. Being compared with Likert's five-grade scale, the average satisfaction degree of each evaluation dimension of DJY's tourism satisfaction is clearly and accurately judged. The satisfaction level of DJY's tourism resources is relatively low, which does not achieve the satisfaction level. Only the tourism environment (4.29) and tourism transportation (4.04) of DJY achieve the satisfaction level. Meaning level (Fig. 1).

Among the 42 evaluation factors of tourist satisfaction in DJY, 8 indexes reached satisfactory level, namely, DJY Water Conservancy Project (4.22), Climate Environment (4.01), Air Quality (4.42), Water Quality (4.37), Scenic Area Civilization (4.05), Scenic Area Health (4.03), External Traffic (4.05), Road Traffic Indicators. The four most unsatisfactory indicators are: Qingcheng Cave classical music (2.99), scenic area crowding (3.33), tour guide (3.5), and special tourist souvenirs (3.17).

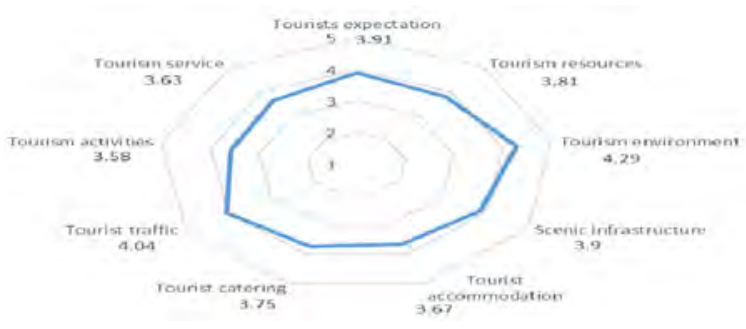

Fig. 1. DJY tourism evaluation dimensions satisfaction.

\section{Analysis of Reliability and Validity of Questionnaire}

Reliability and validity were tested by reliability analysis and factor analysis. Cronbach, s Alpha, i.e. reliability coefficient (a) $=0.97$, and Cronbach, s Alpha coefficients of each evaluation factor are more important than 0.7 , the reliability of the questionnaire is higher. The results of the reliability test showed that the combination reliability $(\mathrm{CR})$ of each variable was greater than 0.7 , which indicated that the measurement reliability of each item to its potential variable was better. The mean variance (AVE) of each variable was greater than 0.5 , indicating that the convergent validity was verified by test.

Table III shows that tourist expectations, tourism resources, tourism environment, scenic infrastructure, tourism accommodation, tourism catering, tourism transportation, tourism activities, tourism services and tourist satisfaction and tourist loyalty have a significant positive correlation; tourist satisfaction and tourist loyalty also show a significant positive correlation.

\section{RESEARCH CONCLUSION}

Based on the analysis of tourist satisfaction in DJY, the following conclusions can be drawn:
Questionnaire statistics show that the majority of young and middle-aged tourists in DJY, mainly working-class enterprise staff, DJY painful life can ease the pressure and relax the mood. Tourists choose more high-speed rail, trains, public services and other means of travel, which is closely related to the construction of traffic routes around DJY.

TABLE III. CORRELATION ANALYSIS BETWEEN EACH ASSESSMENT INDEX AND OVERALL TOURISM SATISFACTION

\begin{tabular}{|l|l|l|l|}
\hline \multicolumn{2}{|c|}{ Influence factor } & \multicolumn{1}{|c|}{$\begin{array}{c}\text { Tourist } \\
\text { satisfaction }\end{array}$} & $\begin{array}{c}\text { Visitor } \\
\text { loyalty }\end{array}$ \\
\hline Tourists expectation & P-values & $0.438^{* *}$ & $.393^{* *}$ \\
\hline Tourism resources & P-values & $.752^{* *}$ & $.693^{* *}$ \\
\hline Tourism environment & P-values & $.570^{* *}$ & $.502^{* *}$ \\
\hline Scenic infrastructure & P-values & $.782^{* *}$ & $.748^{* *}$ \\
\hline Tourist accommodation & P-values & $.642^{* *}$ & $.748^{* *}$ \\
\hline Tourist catering & P-values & $.776^{* *}$ & $.557^{* *}$ \\
\hline Tourist traffic & P-values & $.713^{* *}$ & $.699^{* *}$ \\
\hline Tourism activities & P-values & $.712^{* *}$ & $.624^{* *}$ \\
\hline Tourism service & P-values & $.809^{* *}$ & $.632^{* *}$ \\
\hline
\end{tabular}

Judging from the analysis of tourists'behavior characteristics, it can be found that DJY first-class tourist market is a day-trip tourist in Sichuan Province, with short stay time and low cost. Tourists'motivation is mainly holiday sightseeing and leisure activities, indicating that DJY is a pleasant environment and livable tourist city.

From the satisfaction level of tourists in DJY, it can be seen that tourists'expectation of DJY is between basic satisfaction and satisfaction, and does not reach the satisfaction level; the evaluation of DJY's tourism environment is the highest, reaching the satisfaction level; the other factors are between basic satisfaction and satisfaction; therefore, tourists' expectation of DJY's tourism is between basic satisfaction and satisfaction. The satisfaction degree of tourism is essentially satisfactory. Among them, tourism activities, tourism services and tourist accommodation are the three lowest factors of tourist satisfaction. Relevant departments of DJY tourism can understand the practical needs of tourists accordingly. DJY's tourism policy should be tailored accordingly.

\section{DJY CULTURAL TOURISM DEVELOPMENT STRATEGY BASED ON TOURIST SATISFACTION}

Based on the trend of DJY's tourism policy, tourist satisfaction is very important to enhance the competitiveness of DJY's tourism market. According to the analysis of the survey results, this paper puts forward the following development strategies.

\section{A. Coordinate DJY Tourism Resources and Optimize Tourism Services}

The development of global tourism is to integrate all the tourist attractions of the entire region into a tourist destination. DJY has unique human and natural resources and rich intangible cultural heritage and folk culture, which can completely meet the diversified tourism needs of different tourists. Therefore, reintegrating DJY's tourism resources is of 
great importance to the realization of DJY's global tourism. DJY can explore the historical and cultural connotations of various tourist resources, and promote the development of tourism in DJY city by means of tourist traffic with superior tourist satisfaction.

In the dimension of tourism service, tourists'evaluation of the index "characteristic tourism souvenirs" is very low, so it is very important to develop popular tourism souvenirs that match the image of the tourism destination. From the selection, design, packaging and product propaganda of DJY tourist souvenirs, the cultural elements of DJY are injected in different degrees to enhance the artistic taste of tourist souvenirs, enhance their $\square$ È $\square \square \square \square \grave{E} \%$

$\mathrm{d}$ function. At the same time, it also makes tourist souvenirs become the material carrier to arouse tourists'unique and beautiful tourism experience in the tourist destination. It is useful to improve the service quality of DJY tourism, enhance the attraction of DJY to tourists, and improve the comprehensive evaluation of tourists'tourism experience.

\section{B. Deeply Excavating DJY Cultural Elements to Enhance Brand Awareness of Cultural Tourism}

Global tourism is the integration of tourism resources in the region, being focused on building high-quality scenic spots and implementing brand strategy. In the study of tourists'satisfaction in DJY, the evaluation of DJY water conservancy project is the highest, taking this as the core of resources, combining with QCM "Dao culture", the slogan "Baishui DJY, Baishui DJY" is punched out to develop DJY cultural experience tour and attract more tourists at home and abroad.

The construction of scenic spots is an important part of the brand strategy. The survey shows that tourists'perception of the infrastructure quality of scenic spots is not high, mainly reflected in the crowding degree of scenic spots and tour guide service. DJY's core scenic spots can control the flow of tourists to a certain extent, protect tourism resources and provide a valuable tourism environment for tourists. In terms of tour guides, scenic spots need regular training and assessment of tour guides. By creating a distinctive tourism destination image, creating a tourism destination brand with prominent theme, wide dissemination and high social recognition, enhancing the influence of various tourism brands in the region, and comprehensively promoting the development of cultural tourism in DJY.

\section{Taking Festival Activities as a Carrier to Actively Activate the Intangible Cultural Heritage of DJY}

Excellent traditional culture is the foundation to enhance cultural self-confidence, and the promotion of traditional culture cannot be separated from the carrier of festival activities, festivals are an important barrier to inherit a national spirit and traditional virtues. The study concluded that there are many festivals in DJY, but their satisfaction is low. At present, although the Qingming Drainage Festival has enough historical and cultural background, its participation is weak. The Hongkou Drifting Festival and the Double Legacy Marathon are aimed at specific groups of activities, and they are not attractive to tourists outside the group. In the evaluation index of satisfaction, only selected the representative intangible cultural heritage of DJY, namely Qingcheng Wushu and Qingcheng Dongjing Guyue. The satisfaction of these two evaluation factors has not reached a satisfactory level, and the activation of DJY intangible cultural heritage is imminent.

This paper presents a strategy to promote the activation and development of intangible cultural heritage by festivals. Actively create the intangible cultural tourism festival, carry forward the rich intangible cultural heritage and simple folk customs activities in DJY. It cannot only enhance the participation and experience of festival activities, but also activate the intangible cultural heritage of DJY, and increase the cultural tourism experience of tourists in DJY.

\section{ACKNOWLEDGMENT}

Thank you so much for your guidance on my thesis. I deeply feel the strength of the team in my thesis writing process. At the same time, I would like to acknowledge the authors of the articles cited in this paper, whose shoulders I have completed. I am very grateful to these scholarly pioneers.

\section{REFERENCES}

[1] A. Pizam, Y. Neumann, and A Reichel, "Dimensions of tourist satisfaction with a destination area," J. Annals of Tourism Research, vol. 5(3), pp. 314-322, 1978.

[2] R. Oliver, "L:A Cognitive Model of the Antecedents and Conse-quences of Satisfaction Decisions," J. Journal of Marketing Research, vol. 17(4), pp. 460-469, 1980.

[3] Y. Li, "Tourist Satisfaction and Influence Factor Analysis of Tourist Destinations--A Case Study of Xi'an Domestic Market,” J. Journal of Tourism (In Chinese), vol. 23(4), pp. 43-48, 2008.

[4] X. Wang, Z.H. Liu, and Zhang Hong, "Review and Prospect of Tourist Satisfaction Research," J. Journal of Beijing Second Foreign Language Institute (In Chinese), vol. 32 (1), pp. 22-29, 2010.

[5] X. Wang, F. Cai, and S.Z. Peng, "Research on Multi-level Transformation Model of Local Cultural Elements in Tourism Commodity Development-Taking Beijing as an Example," J. Travel Forum (In Chinese), vol. 10(2), pp. 86-95, 2017.

[6] Y. Qu and Z.P. Jiang, "A Review of Theoretical Research on Tourist Satisfaction in Scenic Spots," J. China Business Review (In Chinese), vol. (31), pp. 174-176, 2012.

[7] S.F. Jin and S.H. Wang, "A review of studies on tourist satisfaction in China in the past decade," J. Journal of Zhoukou Normal University (In Chinese), vol. 27 (6), pp. 127-130, 2010.

[8] K.S. Xu and H.S. Zhu, "Research Progress and Enlightenment of Foreign Tourist Satisfaction," J. Tourism Forum (In Chinese), vol. 1 (4) ,pp. 138-142, 2008.

[9] R.N. Cardozo, “An Experimental Study of Customer Effort, Expectation, and Satisfaction," J. Journal of Marketing Research, vol. 2(3), pp. 244249, 1965.

[10] Q.S. Fu, "A Summary of Theoretical Research on Tourist Satisfaction in Tourist Destinations," J. Geography and Geographic Information Science (In Chinese), vol. 21(5), pp. 90-94, 2005.

[11] Y.F. Xie and Y. Zhang, "Exploration on Tourism Development of Urban Historic and Cultural Blocks Based on Tourist Satisfaction: A Case Study of Nanjing Laomen East Block," J. Market Modernization (In Chinese), vol. (28), pp. 135-137, 2016.

[12] W.Y. Yu, Y.F. Feng, and J.M. Liang, "Research on the Development of Hakka Cultural Tourism Based on Tourist Satisfaction," J. Geographic Science (In Chinese), vol. 33 (7), 824-830, 2013. 